Supplement of Atmos. Chem. Phys., 21, 17167-17183, 2021

https://doi.org/10.5194/acp-21-17167-2021-supplement

(C) Author(s) 2021. CC BY 4.0 License.

(c) (1)
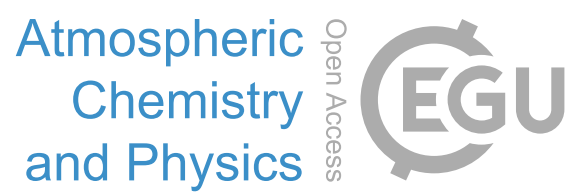

Supplement of

\title{
Response of atmospheric composition to COVID-19 lockdown measures during spring in the Paris region (France)
}

Jean-Eudes Petit et al.

Correspondence to: Jean-Eudes Petit (jean-eudes.petit@1sce.ipsl.fr)

The copyright of individual parts of the supplement might differ from the article licence. 


\section{Supplementary material}

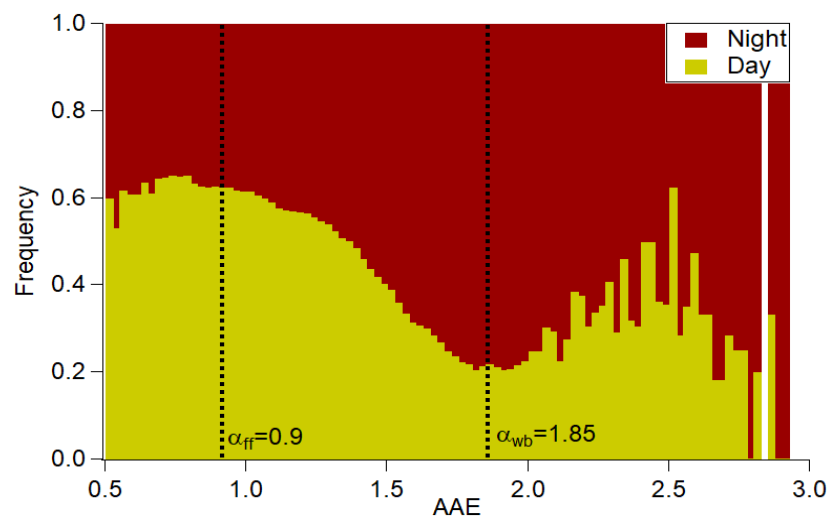

Figure S1 Diurnal variations of AAE between night and day hours. Night and day were defined as UTC $18 \mathrm{~h} 00-5 \mathrm{~h} 00$ and $6 \mathrm{~h} 00-17 \mathrm{~h} 00$, respectively.

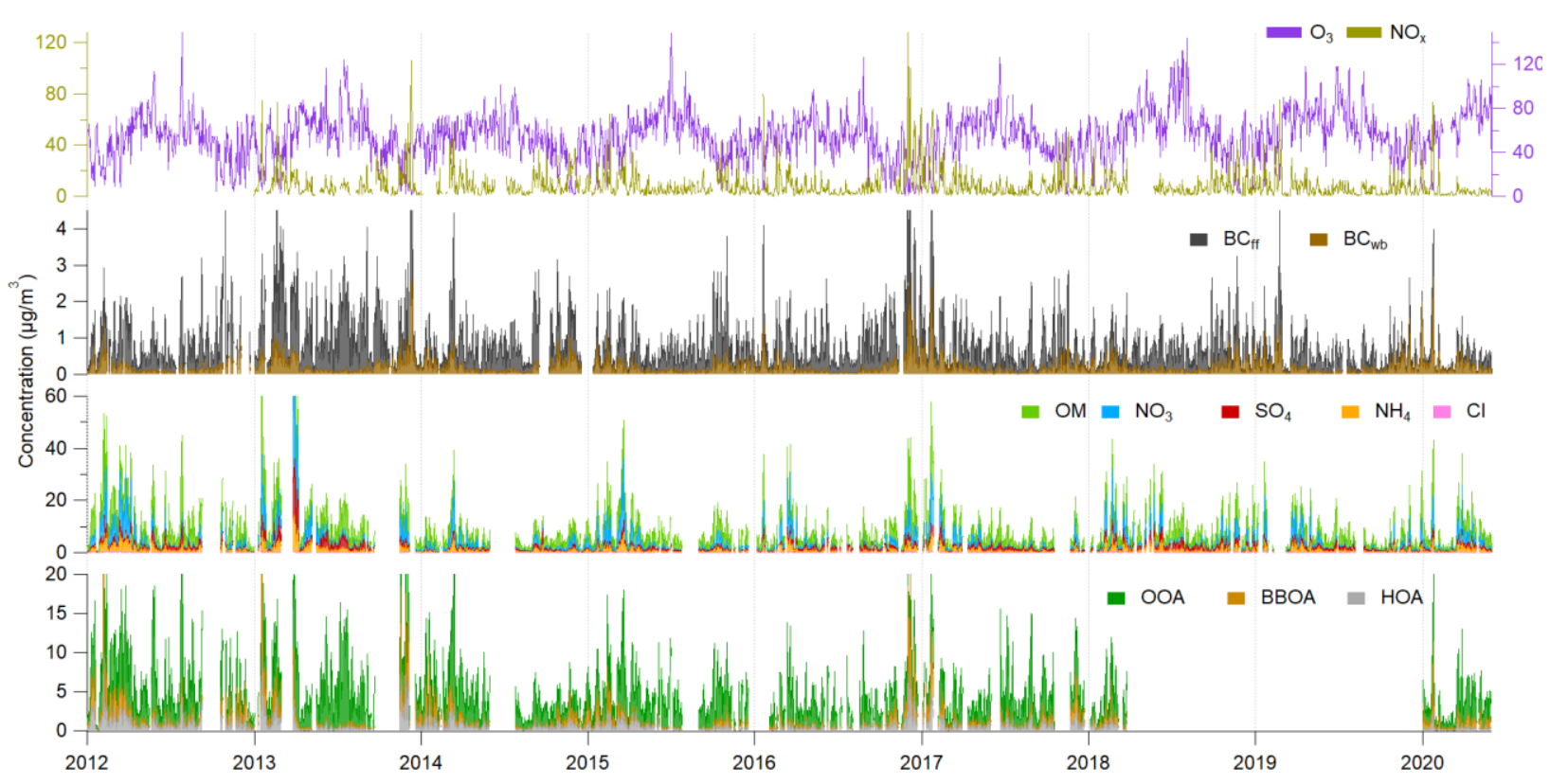

Figure S2 Concentration timeseries (daily average, $\mu \mathrm{g} / \mathrm{m}^{3}$ ) of the in-situ dataset used in this study. 


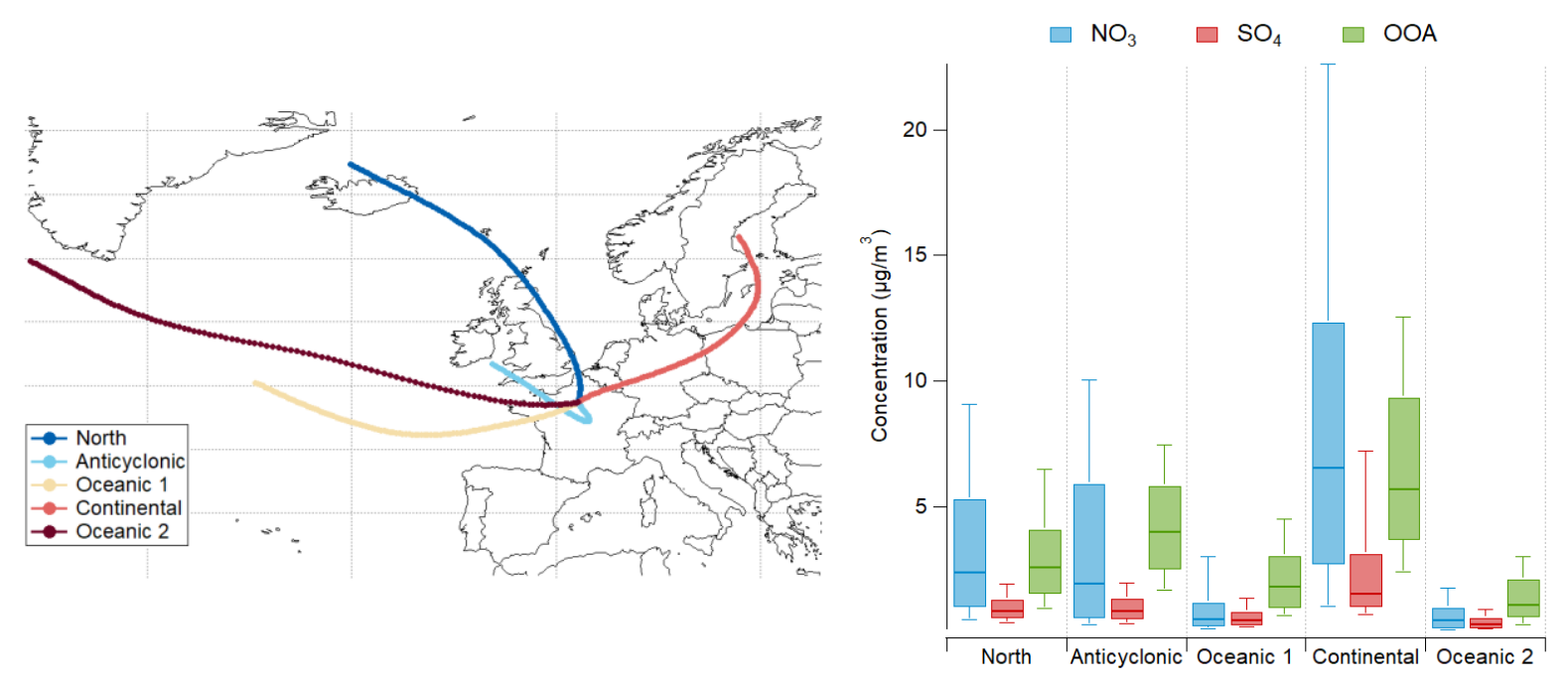

Figure S3 a) Mean trajectory clusters during LP2012-2020. b) distribution of $\mathrm{NO}_{3}, \mathrm{SO}_{4}$ and OOA concentrations during LP2012-2020 within each cluster.

\begin{tabular}{|c|c|c|c|c|c|c|}
\hline & & LP2020 & LP2019 & LP2017-2019 & LP2015-2019 & LP2012-2019 \\
\hline \multirow{5}{*}{$\begin{array}{c}\text { Temperature } \\
\left({ }^{\circ} \mathrm{C}\right)\end{array}$} & $\min$ & 4.2 & 5.31 & -0.5 & -0.5 & -0.5 \\
\hline & $\max$ & 19.7 & 19.8 & 23.2 & 23.2 & 23.2 \\
\hline & mean & 12.9 & 10.6 & 11.1 & 11.0 & 10.6 \\
\hline & MB & & 2.2 & 1.8 & 1.9 & 2.3 \\
\hline & $\mathrm{r}$ & & 0.17 & 0.4 & 0.45 & 0.45 \\
\hline \multirow{5}{*}{ RH $(\%)$} & $\min$ & 34.0 & 36.9 & 36.9 & 36.9 & 34.9 \\
\hline & $\max$ & 87.5 & 84.7 & 92.0 & 96.6 & 100 \\
\hline & mean & 56.0 & 65.2 & 66.0 & 67.1 & 69.0 \\
\hline & MB & & -9.1 & -9.9 & -11.0 & -13.1 \\
\hline & $\mathrm{r}$ & & 0.36 & 0.32 & 0.28 & 0.30 \\
\hline \multirow{5}{*}{$\begin{array}{l}\text { Wind Speed } \\
\qquad(\mathrm{m} / \mathrm{s})\end{array}$} & $\min$ & 0.8 & 0.3 & 0.3 & 0.3 & 0.3 \\
\hline & $\max$ & 6.9 & 5.2 & 5.2 & 7.5 & 7.5 \\
\hline & mean & 2.5 & 2.5 & 2.5 & 2.6 & 2.6 \\
\hline & MB & & -0.03 & -0.01 & -0.13 & -0.16 \\
\hline & $r$ & & -0.09 & 0.07 & 0.31 & 0.23 \\
\hline \multirow{5}{*}{$\begin{array}{l}\text { Pressure } \\
\text { (hPa) }\end{array}$} & $\min$ & 982.0 & 975.4 & 975.4 & 975.4 & 971.5 \\
\hline & $\max$ & 1009.0 & 1012.5 & 1014.5 & 1014.7 & 1015.5 \\
\hline & mean & 996.5 & 996.0 & 995.7 & 996.0 & 995.1 \\
\hline & MB & & 0.9 & 0.72 & 0.49 & 1.43 \\
\hline & $\mathrm{r}$ & & 0.13 & 0.03 & 0.08 & 0.05 \\
\hline
\end{tabular}

Table S1: Meteorological conditions during LP2020, LP2019, LP2017-2019, 2015-2019 and 2012-2019. Min, max and average values for Temperature, RH, Wind speed and Pressure are presented for each period. $\mathrm{MB}$ and $\mathrm{r}$ are calculated through through a daily reconstruction of daily values of LP2020. 


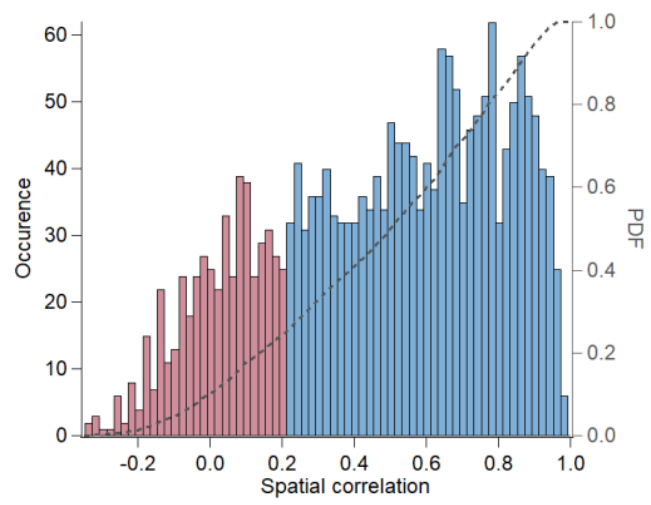

Figure S4: Distribution of spatial correlation between each day of LP2020 and each corresponding analog day. Red bars correspond to non-satisfactory analogs.

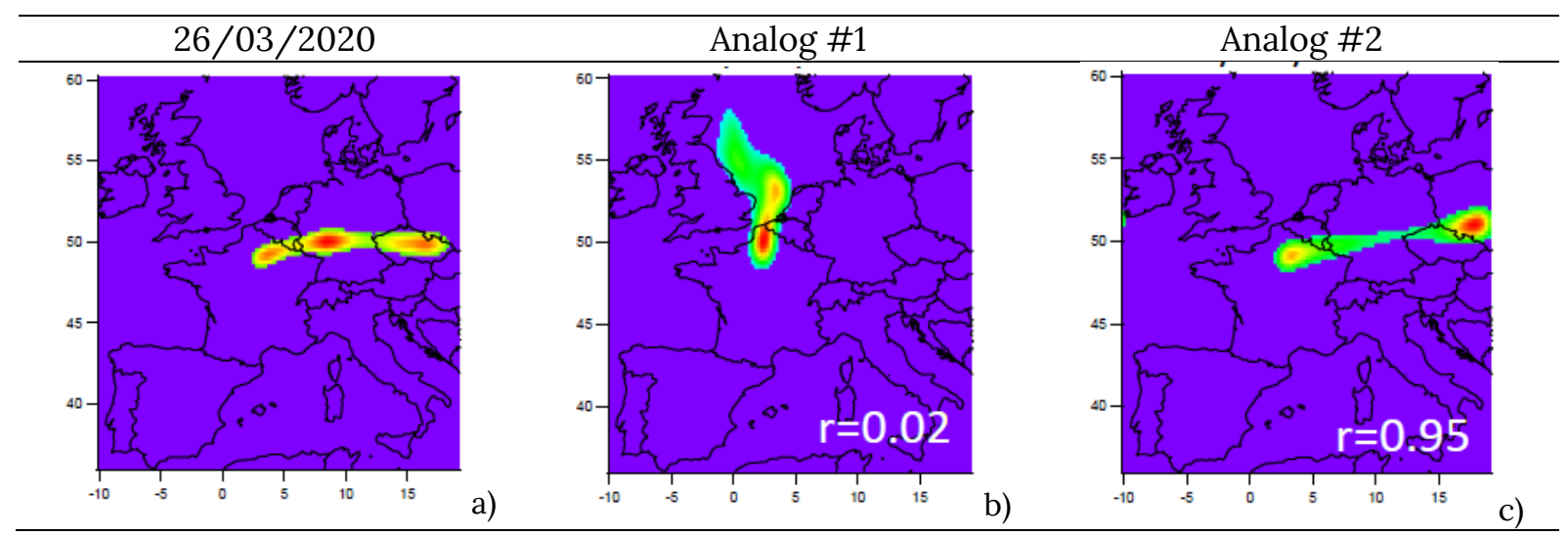

Figure S5 Origin of air masses arriving at SIRTA. a) on March, $26^{\text {th }} 2020$; b) for one analog day from synoptic circulation analysis; c) for another day of the analog list. Pearson correlation coefficients are shown on the plot 


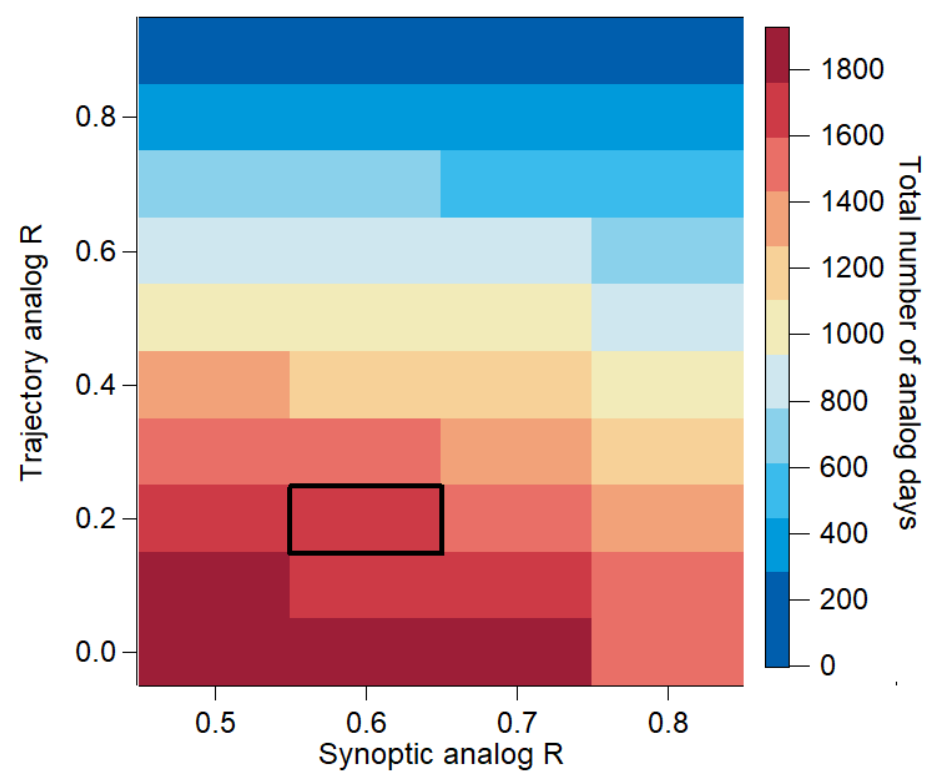

Figure S6 Influence of correlation coefficients on the total number of analog days. Black box corresponds to the scenario used in the main text.

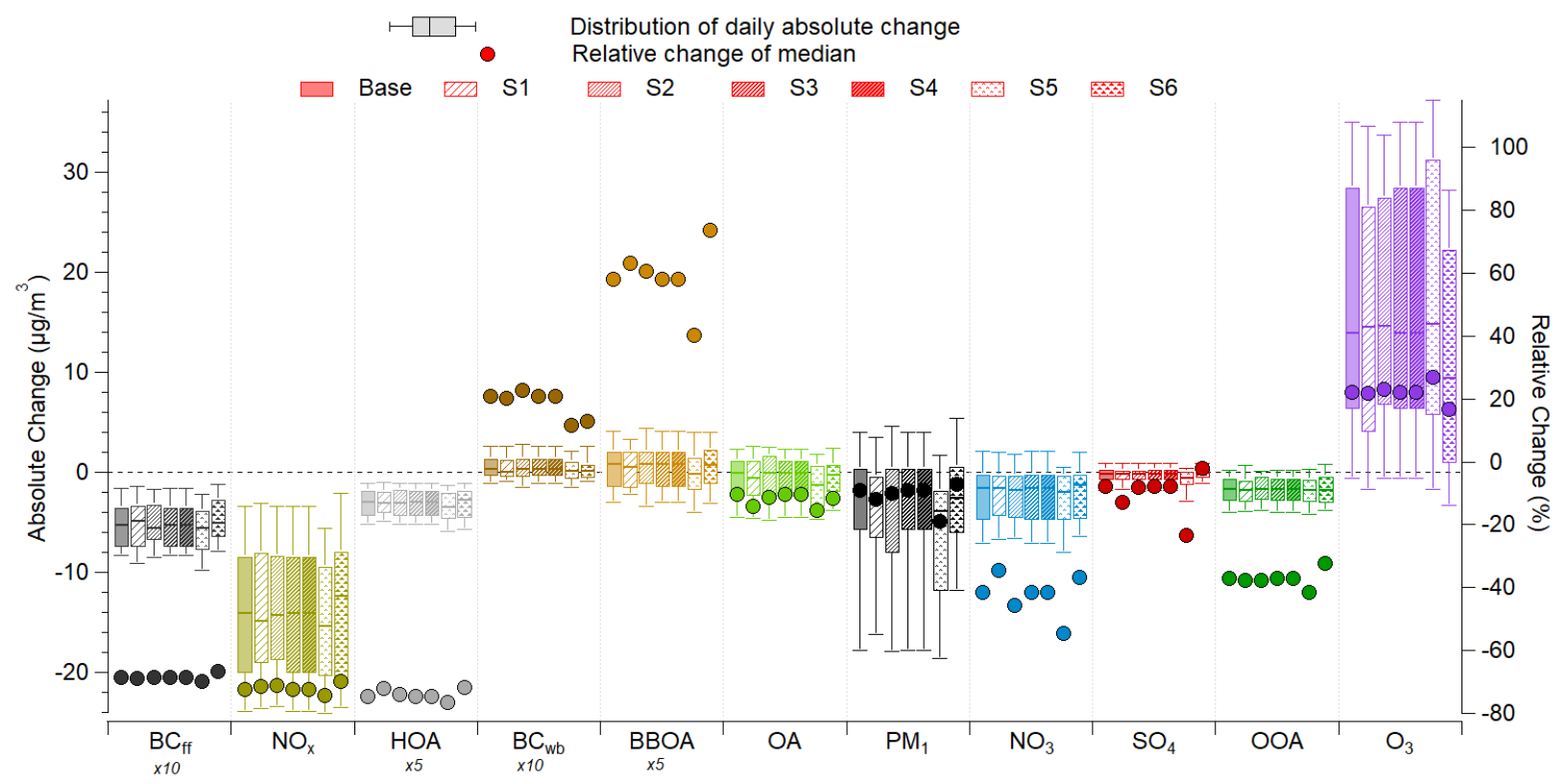

Figure S7 Absolute and relative changes of ambient concentrations of reactive gases and particulate pollutants due to lockdown, calculated for different analog scenarios (Table 2). Left axis: Boxplots represent the distribution of daily absolute change $\left(\mu \mathrm{g} / \mathrm{m}^{3}\right) ; 10^{\text {th }}, 25^{\text {th }}, 50^{\text {th }}, 75^{\text {th }}$ and $90^{\text {th }}$ percentiles were used. $\mathrm{BC}_{\mathrm{ff}}, \mathrm{HOA}, \mathrm{BC}_{\mathrm{wb}}$ and $\mathrm{BBOA}$ concentration changes have been scaled for clarity. Right axis: Round markers refer to the relative change $(\%)$ of median concentrations. 

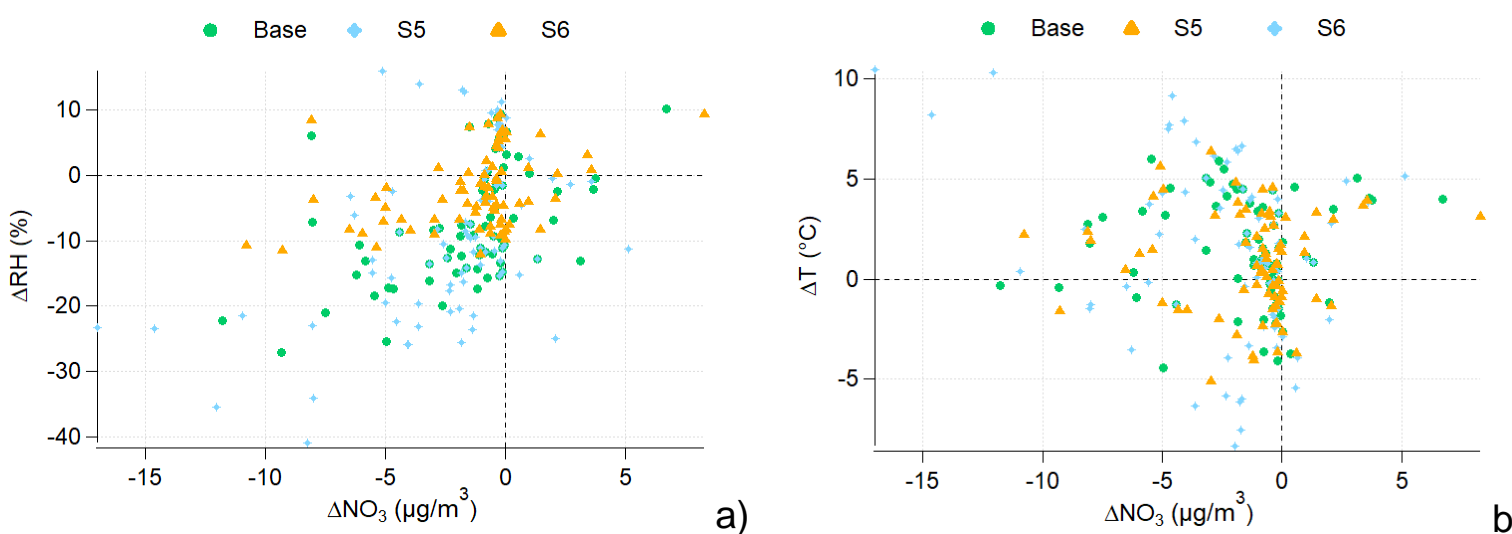

Figure S8 Influence of meteorological filtering on the concentration change of $\mathrm{NO}_{3}$. Daily concentration change of $\mathrm{NO}_{3}$ versus $\mathrm{RH}(\mathrm{a})$ and temperature (b) change for Base, S5 and S6 scenarios.

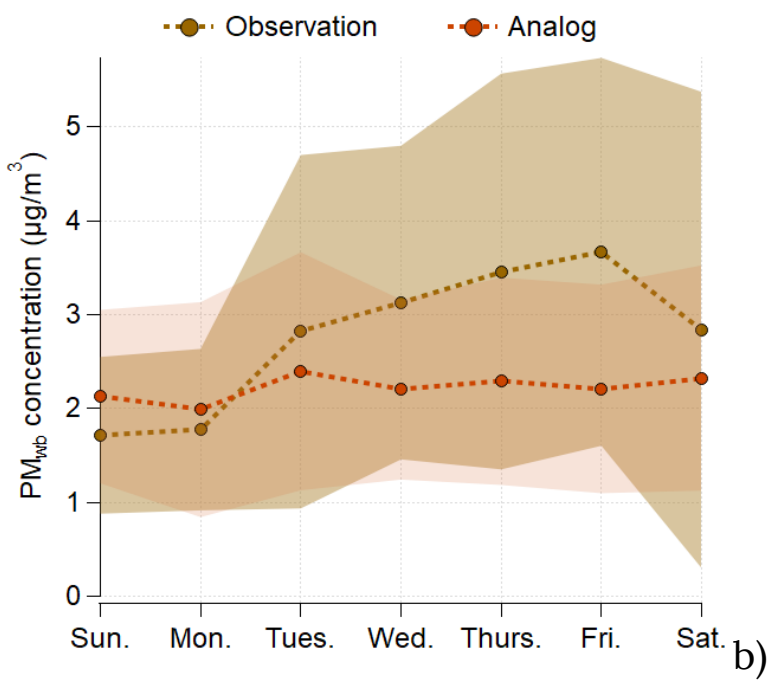

Figure S9 Weekly variations of $\mathrm{PM}_{\mathrm{wb}}$ during lockdown (mean \pm standard deviation) for the observed (brown) and analog (dark red) dataset. 


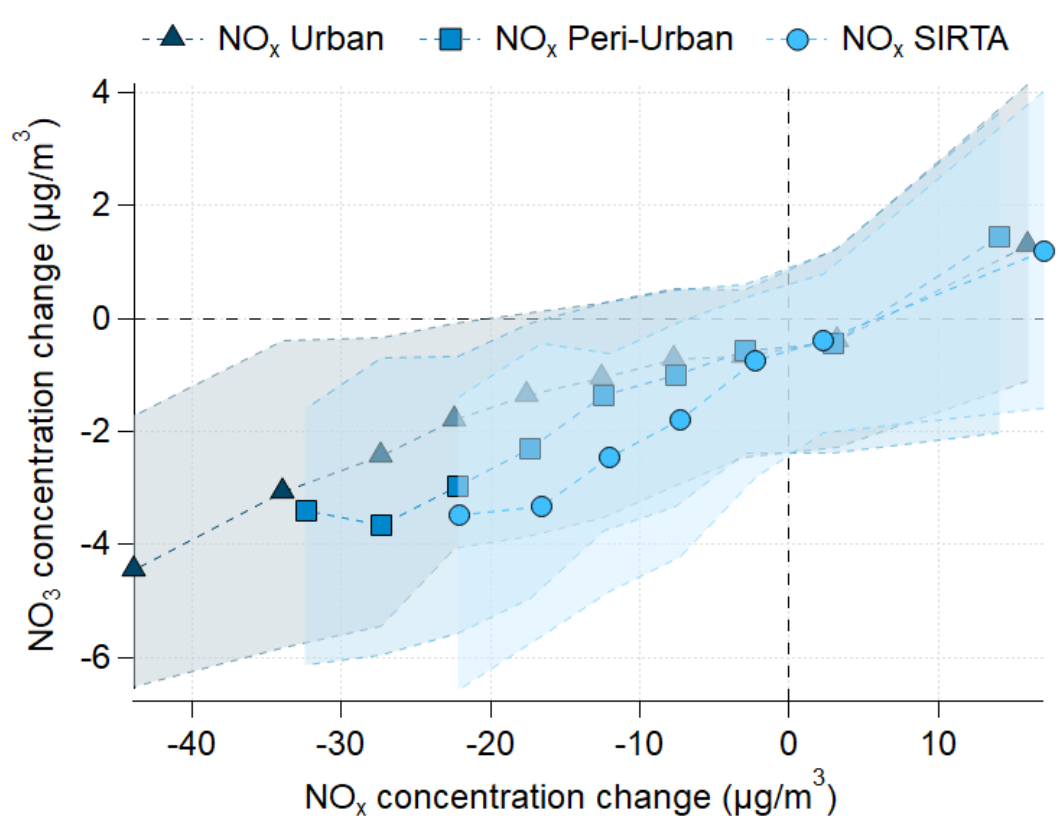

Figure S10 Concentration change of $\mathrm{NO}_{3}$ vs concentration $\mathrm{NO}_{\mathrm{x}}$ at different backgrounds (SIRTA, urban and peri-urban).

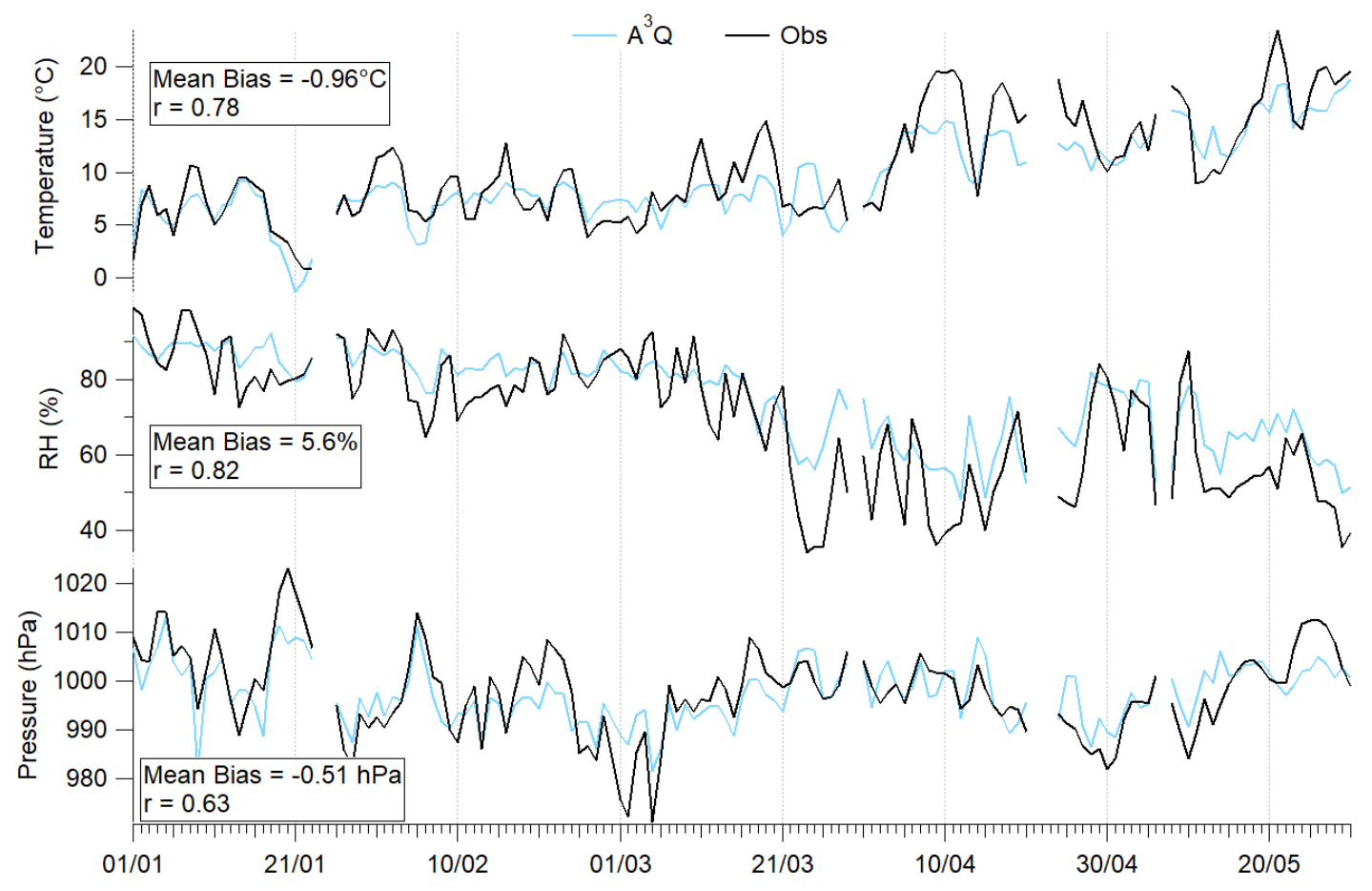

Figure S11. Temporal variations of ambient temperature, $\mathrm{RH}$ and pressure during January-May 2020, observed (black) and estimated by $A^{3} Q$ (blue) 